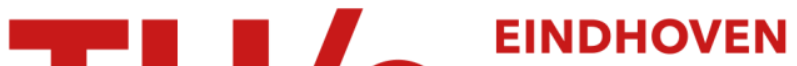 UNIVERSITY OF TECHNOLOGY
}

\section{Fully passive user localization for beam-steered high-capacity optical wireless communication system}

Citation for published version (APA):

Koonen, A. M. J., Mekonnen, K. A., Huijskens, F. M., Cao, Z., \& Tangdiongga, E. (2020). Fully passive user localization for beam-steered high-capacity optical wireless communication system. Journal of Lightwave Technology, 38(10), 2842 - 2848. [9035443]. https://doi.org/10.1109/JLT.2020.2980428

DOI:

10.1109/JLT.2020.2980428

Document status and date:

Published: 15/05/2020

Document Version:

Author's version before peer-review

Please check the document version of this publication:

- A submitted manuscript is the version of the article upon submission and before peer-review. There can be important differences between the submitted version and the official published version of record. People interested in the research are advised to contact the author for the final version of the publication, or visit the $\mathrm{DOI}$ to the publisher's website.

- The final author version and the galley proof are versions of the publication after peer review.

- The final published version features the final layout of the paper including the volume, issue and page numbers.

Link to publication

\section{General rights}

Copyright and moral rights for the publications made accessible in the public portal are retained by the authors and/or other copyright owners and it is a condition of accessing publications that users recognise and abide by the legal requirements associated with these rights.

- Users may download and print one copy of any publication from the public portal for the purpose of private study or research.

- You may not further distribute the material or use it for any profit-making activity or commercial gain

- You may freely distribute the URL identifying the publication in the public portal.

If the publication is distributed under the terms of Article $25 \mathrm{fa}$ of the Dutch Copyright Act, indicated by the "Taverne" license above, please follow below link for the End User Agreement:

www.tue.nl/taverne

Take down policy

If you believe that this document breaches copyright please contact us at:

openaccess@tue.nl

providing details and we will investigate your claim. 


\title{
Fully Passive User Localization for Beam-Steered High-Capacity Optical Wireless Communication System
}

\author{
Ton Koonen, Fellow, IEEE, Fellow, OSA, Ketemaw Mekonnen, Student Member, IEEE, \\ Frans Huijskens, Ngoc-Quan Pham, Zizheng Cao, Member, IEEE, \\ Eduward Tangdiongga, Member, IEEE
}

\begin{abstract}
By means of narrow infrared beams very high capacity wireless links can be set up to users individually, while also offering high privacy and high energy efficiency. Accurate device localization for steering the beams is required. This has been achieved within the $10 \mathrm{~cm}$ pico-cell resolution of a $2 \mathrm{D}$ beamsteered optical wireless communication system by applying a matrix of miniature corner-cube retro-reflectors. The localization process is self-calibrating, and does not need power-consuming elements at the receiver. In an indoor laboratory system setup, real-time transfer of multiple $10 \mathrm{GbE}$ high-definition video streams has been demonstrated.
\end{abstract}

Index Terms - Optical wireless communication, optical beam steering, wavelength routing, optical retro-reflector, device localization

\section{INTRODUCTION}

As the radio spectrum is getting seriously overcrowded due to the booming needs for wireless connectivity, new spectrum opportunities need to be found. The optical spectrum readily offers these: the visible spectrum $(400-700 \mathrm{~nm}$, used amongst others for illumination) offers no less than $320 \mathrm{THz}$ of spectrum, and the infrared (IR) spectrum from 1500 to $1600 \mathrm{~nm}$ as used extensively in high-capacity optical fiber networks offers a respectable $12.5 \mathrm{THz}$. Both the visible spectrum and the IR spectrum significantly exceed what can be reached with radio mm-wave techniques, even with sub-THz techniques.

Visible light communication (VLC) is typically using existing LED systems; these are primarily optimized for illumination, not for data transmission. Thus, their bandwidth is limited; moreover, their large footprint implies that this bandwidth is to be shared among many devices. A networked version of many small LED cells can increase the capacity per user, but at the cost of higher complexity [1].

Another option for optical wireless communication (OWC) is to use narrow infrared optical beams. These beams need to be accurately steered to the users, and give each user an unshared personal wireless channel which can readily carry multiple Gbit/s [2]. Systems have been reported which steer the beams

Manuscript submitted Nov. 15, 2019. This work was supported by the European Research Council under the Proof-of-Concept Advanced Grant project BROWSE+ - Beam-steered Reconfigurable Optical-Wireless System for Energy-efficient communication. (Corresponding author: Ton Koonen.) with MEMS mirrors [3], or with spatial light modulators [4]. In these systems, each beam needs a separate steering element which has to be controlled over a control channel. We reported the steering of narrow IR beams by means of a passive diffractive module based on a pair of crossed gratings, or on an arrayed waveguide router with 2-dimensionally arranged output fiber array [2]. Each beam is two-dimensionally steered by just changing its wavelength remotely in the associated transmitter. Thus, the beam's wavelength acts as both the carrier of the data and as the control channel, so the control channel is embedded in the data channel and no separate control channel is needed. Each beam constitutes an ultra-high capacity wireless link addressing a single device; hence, it basically has the virtues of a fiber connection to the device, but without needing a fiber. Because a beam will be directed to go only there where and when needed, it is very power-efficient (not spoiling energy to places where it is not needed) and offers high privacy (reaching only the intended device, no others receive anything so cannot listen in). As the light travels through air, not through fiber, the optical link constituted by a beam has minimum latency $(3.3 \mathrm{~ns} / \mathrm{m}$ in air, versus $5 \mathrm{~ns} / \mathrm{m}$ in silica fiber). And it has intrinsically an even higher bandwidth than fiber as it is not hampered by waveguide dispersion. Moreover, IR light is 'eyesafe' beyond $1400 \mathrm{~nm}$, hence significantly higher power levels (up to $10 \mathrm{~mW}$ ) can be transmitted than in visible light safely according to the eye safety standards [5]. The thus attainable high link power budget enables multi-Gbit/s data rates per beam. And the narrowness of a beam enables high spatial multiplicity, hence another significant increase of attainable data throughput.

For appropriately directing the narrow IR beams the location of the user device needs to be known accurately. Various device localization techniques employing RF signals emitted or processed by the user have been reported, using triangular algorithms such as RSS (received signal strength), AoA (angle of arrival), and TDoA (time difference of arrival) [6]. Also device localization techniques employing VLC signals have been reported, using multiple luminaires and signal processing at the user device [7]. Localization by means of a camera which

The authors are with the Institute for Photonic Integration, Eindhoven University of Technology, Eindhoven 5612 AE, The Netherlands (e-mail: a.m.j.koonen@tue.nl ; k.a.mekonnen@tue.nl ; f.m.huijskens@tue.nl ; n.q.pham@tue.nl; z.cao@tue.nl; e.tangdiongga@tue.nl). 
determines the position of user devices by observing active LED tags on them has been reported in [8]. High localization accuracies within a few $\mathrm{mm}$ have been achieved. However, in each of these techniques there is a need for active functions in the user device, which draws extra power from the mobile device and thus compromises its battery lifetime.

We propose a novel device localization concept which only requires a simple fully passive function at the user device, thus not draining the device's battery, while building on our highcapacity IR beam-steered OWC system [9][10]. We have validated this localization concept in a laboratory system experiment in which multiple high-definition video streams were carried by narrow infrared beams.

\section{IR BEAM-STEERED OWC SYSTEM}

Our indoor beam-steered OWC system concept is shown in Fig. 1. The (Fiber-to-the Home, FttH) access network is terminated at the entry of the house in a central communication unit, and from there the services are routed to the individual rooms by a fiber network. At the ceiling of each room, pencil beam radiating antennas (PRAs) launch the narrow IR beams to the respective mobile devices. A PRA is fully passive, and contains optical diffractive elements which two-dimensionally direct each beam into a direction determined by the signal's wavelength.

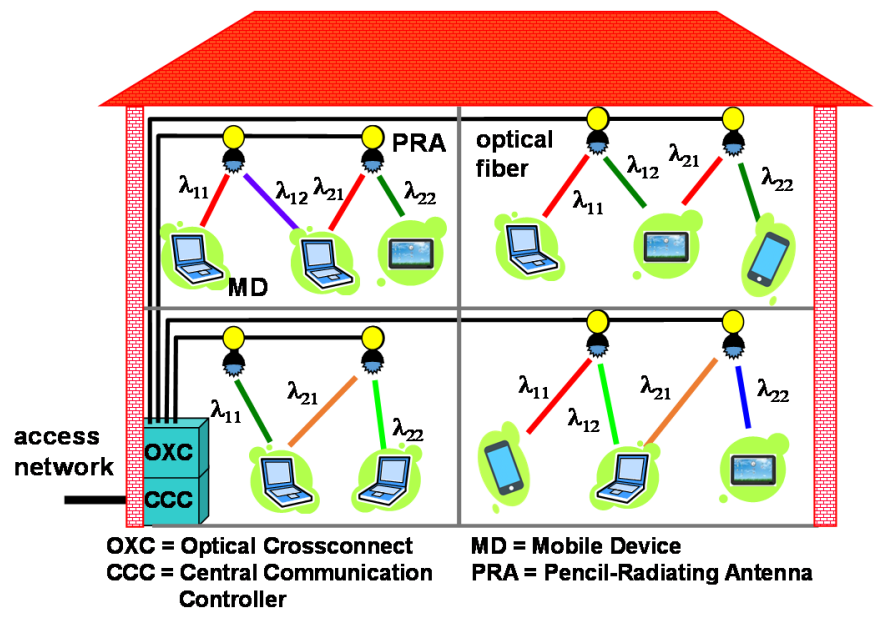

Fig. 1 Beam-steered indoor OWC system

We explored two options for implementing such a PRA [2]: by means of a pair of orthogonally-crossed diffraction gratings, and alternatively by means of an arrayed waveguide grating router (AWGR) with a high number of output fiber ports arranged in a 2D fiber array which is put in front of a lens, as shown in Fig. 2. Each incoming wavelength is by the AWGR routed to a specific fiber in this array, with its specific position with respect to the lens, and therefore after the lens is emitted as a beam into a specific direction. As shown in Fig. 3, the 2D fiber array is preferably positioned closer to the lens than the lens' focal plane, which yields slightly diverging beams [9]. This defocusing yields a more compact PRA module, and a coverage of the user plane which is less dependent on the user's distance to the lens. From the design condition that neighbouring beam spots in the image plane should touch each other for optimum coverage of the user area, and given a desired spot diameter required for adequate received power by the detector's optical aperture, the lens' focal length $f$ and the fiber pitch $\Delta y$ in the 2D fiber array can be calculated [9].

In our previously reported system demonstrator [9], we deployed the AWGR-based PRA. Device localization was done by means of a $60 \mathrm{GHz}$ beam which was sent by the mobile device and was found by a scanning horn antenna positioned next to the PRA. Reading the mechanical 2D angular coordinates of this scanning antenna enabled to discover the $(\mathrm{x}, \mathrm{y})$ position of the user device, and subsequently the IR beam's wavelength was tuned such that the beam was pinpointed accurately to the device. Obviously, sending of the $60 \mathrm{GHz}$ beam draws power from the device's battery.

We recently reported device localization by means of a camera mounted at the ceiling which can observe the room and localize multiple user devices simultaneously [11]. Each user device has four visible LED tags surrounding its receiving optical aperture. These tags blink in a specific sequence which acts as the ID of that device, and for this operation have to draw some power from the battery of the user's device. After processing the images captured by the camera and subsequently having determined the position coordinates of the devices, these positions have to be mapped and calibrated to the specific wavelengths which direct the beams to those locations. A localization accuracy of less than $5 \mathrm{~mm}$ over a reach of $3 \mathrm{~m}$ was achieved.

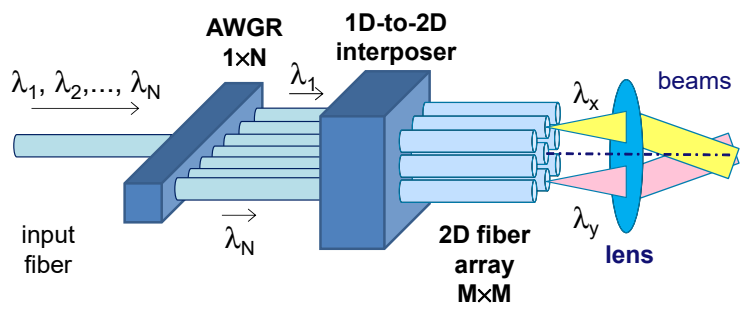

Fig. 2 2D beam steerer based on a high port count AWGR

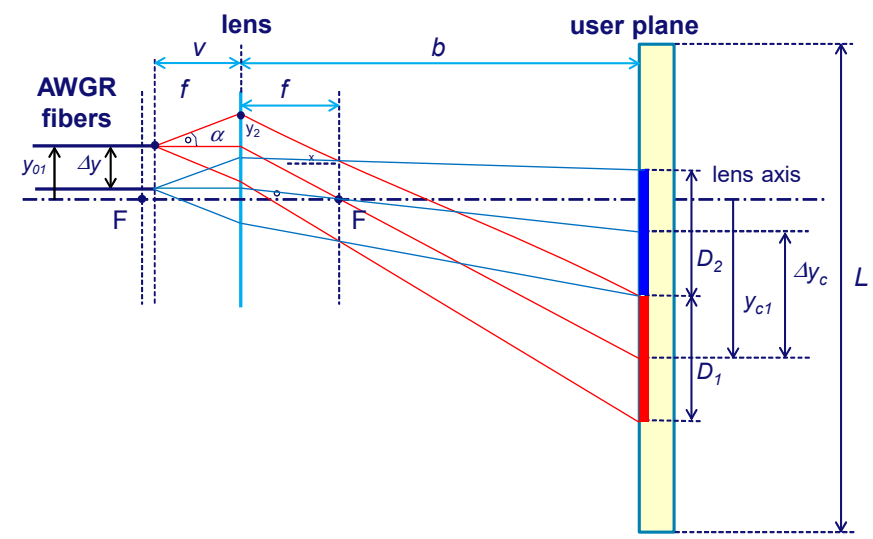

Fig. 3 Design of the AWGR-based beam steerer with defocussed 2D fiber array

\section{PASSIVE DEVICE LOCALIZATION}

To enable localization of the user's device without drawing power from it, we explored how to equip the device with passive means for that, in particular a passive retroreflector based on an optical corner cube (CC) [10]. A CC reflects light rays in the same direction as they came from, but there is a displacement between incoming and reflected rays, as is 
analysed in Fig. 4. The magnitude of this displacement $\Delta$ is dependent on the entry point of the incoming ray into the $\mathrm{CC}$, and on the incident angle $\alpha$ with respect to the main axis of the CC. The maximum displacement $\Delta_{\max }$ is proportional to the entry aperture $D$ of the $\mathrm{CC}$; for the $2 \mathrm{D}$ case shown in Fig. 4 , it follows that

$$
\Delta=2 h=2 L \cdot \sin (\pi / 4-\alpha) \leq D \sqrt{2} \sin (\pi / 4-\alpha)=\Delta_{\max }
$$

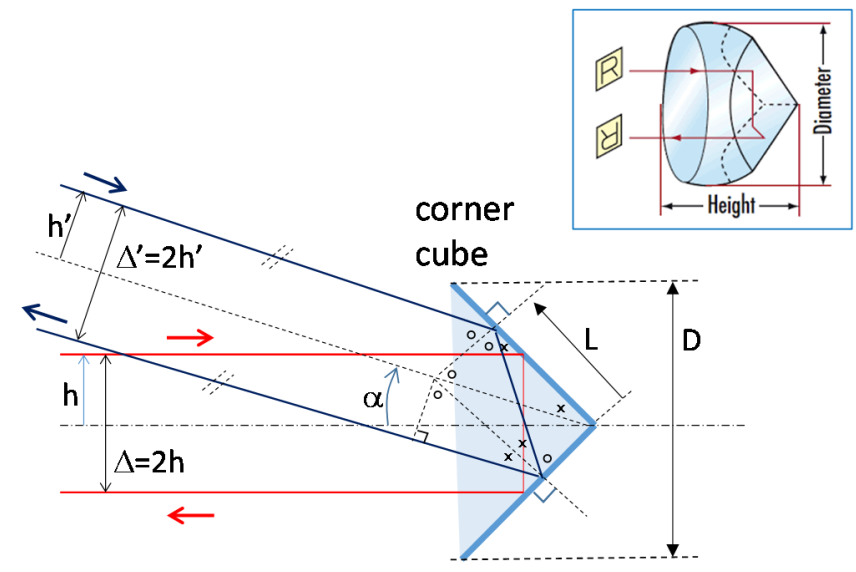

Fig. 4 Ray paths in optical corner cube reflector (inset: 3D view)

As illustrated in Fig. 5, a retro-reflecting $\mathrm{CC}$ mounted on the user device's OWC receiver will direct part of the incoming narrow IR beam back to the PRA, into the AWGR output port it came from. From the AWGR's input port, the reflected signal is subsequently returned to the central site, where via an optical circulator it is monitored in the localization processor. This processor is controlling the wavelength of the tunable laser diode. The device localization process begins by a command from the localization processor to the tunable laser diode to start scanning the room with an IR beam by sweeping its wavelength. As soon as the processor detects a returning reflected signal, it halts and stores the actual wavelength of the tunable laser, and thus has found and stored the location of the user device. The laser is then set to this wavelength, and by the correspondingly steered IR beam the system has established a high-speed wireless communication link to the user. In this way, the localization is self-calibrating: the device position is directly mapped to the wavelength needed for directing the beam, and no separate calibration is needed.

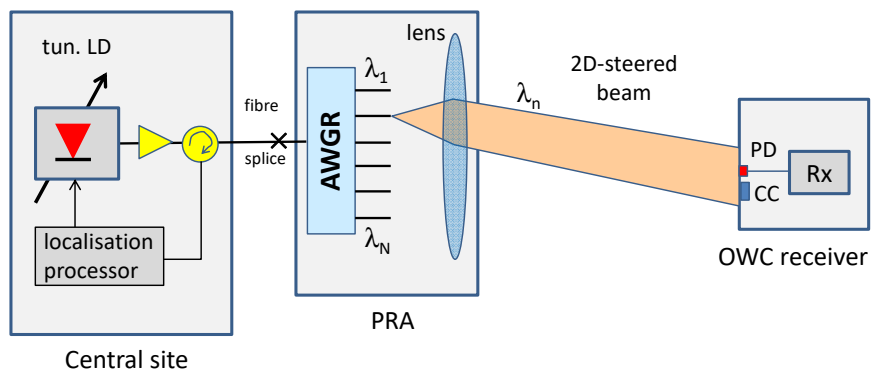

Fig. 5 Localising the user's OWC receiver by means of a retro-reflecting corner cube $(\mathrm{CC})$

As reported before [9], to achieve a compact design of the PRA it is required to position the 2D fiber array of the AWGR outputs not in the focal plane of the lens, but a bit closer to it; i.e. to introduce an amount of defocusing $p=1-v / f>0$ (see Fig. 3). Next to a reduction of the PRA's size, this defocusing yields a slight divergence of the beams, which improves the coverage of the user plane and makes the coverage less dependent on the actual distance to the lens; this relaxes the device mobility requirements. But the defocusing makes that the displaced beam returning from the $\mathrm{CC}$ may not end in the same fiber port as where it came from; see Fig. 6. At the fiber plane, this lateral offset $\delta$ of the returning beam is

$$
\delta=\frac{f-v}{f} \cdot \frac{\Delta}{\cos \alpha} \leq p \cdot D_{C C} \cdot(1-\tan |\alpha|)
$$

To minimize this offset issue, it is preferred that the displacement $\Delta$ is minimized, and therefore the aperture $\mathrm{D}_{\mathrm{CC}}$ of the $\mathrm{CC}$ is minimized. But this implies that only a very small fraction of the beam is retro-reflected, which compromises the detection process. We therefore opted to apply not a single small CC, but a matrix of many miniature CC-s. Such CC arrays are readily available in retro-reflecting foils; these are commercially available and are widely used already, e.g. for road signage. We acquired such a foil containing a fine pattern of miniature molded CC-s (from Orafol [12]); Fig. 7 shows a microscopic view of its structure; the diameter of a $\mathrm{CC}$ in it is about $100 \mu \mathrm{m}$.

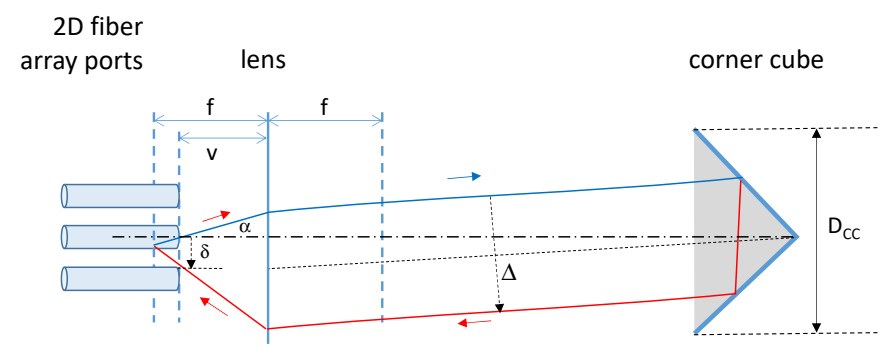

Fig. 6 Operating the retro-reflecting $\mathrm{CC}$ in a defocused PRA

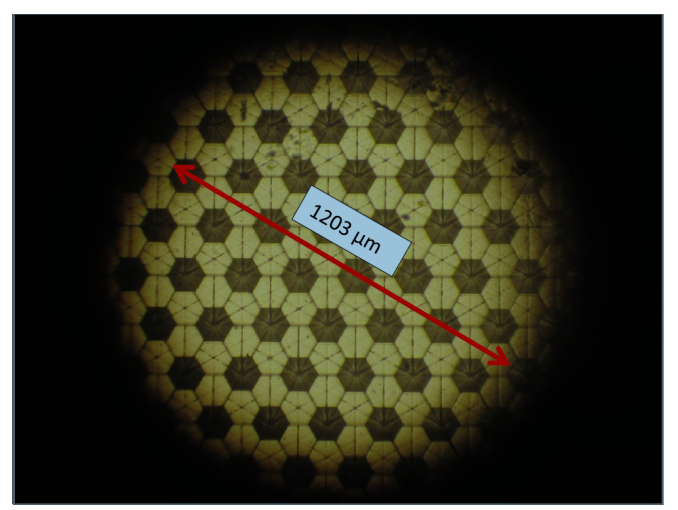

Fig. 7 Foil with many miniature corner cubes, each with a diameter of $100 \mu \mathrm{m}$ (from Orafol)

With 2D ray tracing, the impact of defocusing on the lateral offset $\delta$ when applying a matrix of $\mathrm{CC}$-s has been assessed. A lens with focal length $f=50 \mathrm{~mm}$ and negligible aberrations was assumed, and a CC matrix foil with diameter of $35 \mathrm{~mm}$. In the system design for indoor application, a distance lens-CC matrix $b=2.5 \mathrm{~m}$ was assumed. With a fiber $\mathrm{NA}=0.1$, the beam diameter at the CC matrix was about $10 \mathrm{~mm}$ when the $2 \mathrm{D}$ fiber array is in focus (so $p=0$ ), and $108 \mathrm{~mm}$ when the $2 \mathrm{D}$ fiber array is $20 \%$ defocussed $(p=0.2)$. Fig. 8 shows the ray tracing results; the blue rays are running towards the $\mathrm{CC}$ matrix, and the red rays 
are returning from the $\mathrm{CC}$ matrix. The impact of the $\mathrm{CC}$ diameter has been analysed by considering CC-s with diameter $D_{C C}=100 \mu \mathrm{m}$ and $=1 \mathrm{~mm}$. No lateral offset occurs when the $2 \mathrm{D}$ fiber array is in focus $(p=0)$; Fig. 8.a shows the collimated beam for the whole lens-to-CC matrix link, and Fig. 8.b the situation at the endface of a fiber in the $2 \mathrm{D}$ array. But when defocussing is introduced, e.g. $p=0.2$, a lateral offset $\delta$ occurs which is about
$20 \%$ of the CC's diameter. Fig. 8.c shows the diverging beam for the lens-to-CC matrix link for $D_{C C}=100 \mu \mathrm{m}$. Only a part of the beam falls onto the CC matrix (with diameter $35 \mathrm{~mm}$ ) and is returned (red rays); the remainder of the beam is not returned. Fig. 8.d shows the lateral offset of the returning rays at the fiber endface in a zoomed-in view. Fig. 8.e and Fig. 8.f show similar ray tracings, but for $D_{C C}=1 \mathrm{~mm}$. These show the clear increase

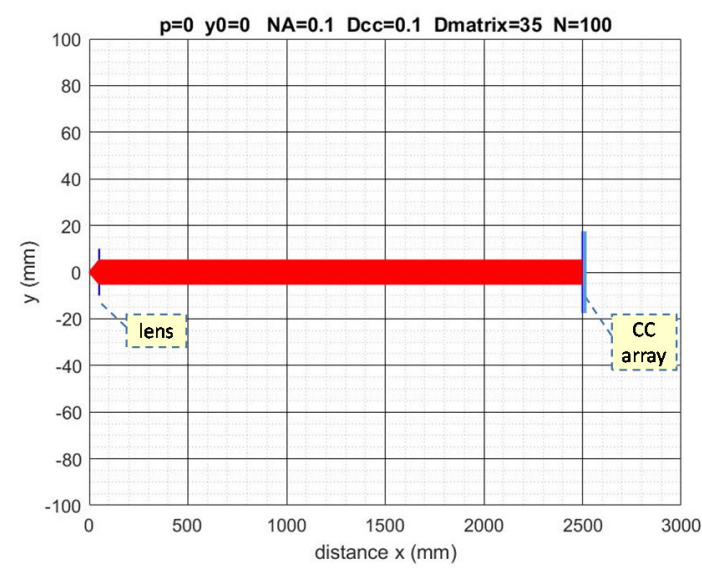

a) Focused $(p=0), \mathrm{CC}$ aperture $D_{C C}=100 \mu \mathrm{m}$

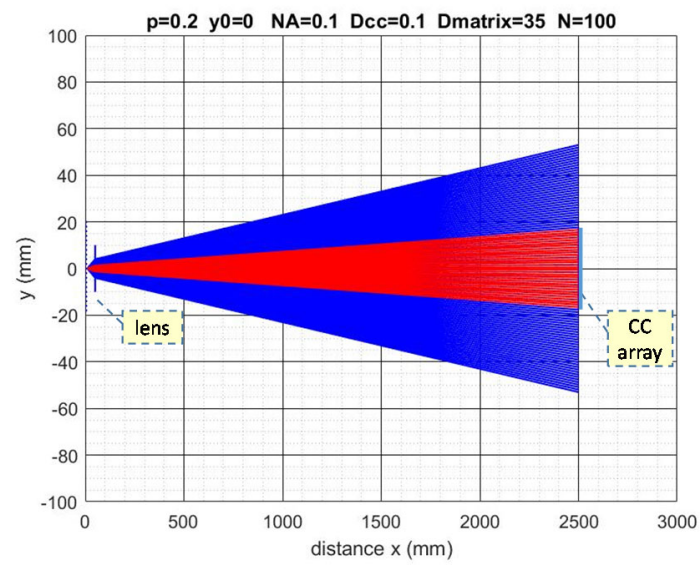

c) Defocused ( $p=0.2), \mathrm{CC}$ aperture $D_{C C}=100 \mu \mathrm{m}$

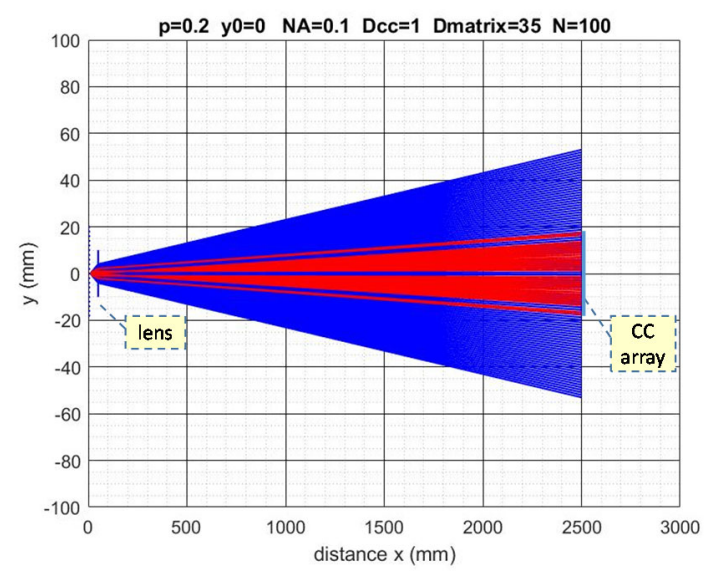

e) Defocused ( $p=0.2), C C$ aperture $D_{C C}=1 \mathrm{~mm}$

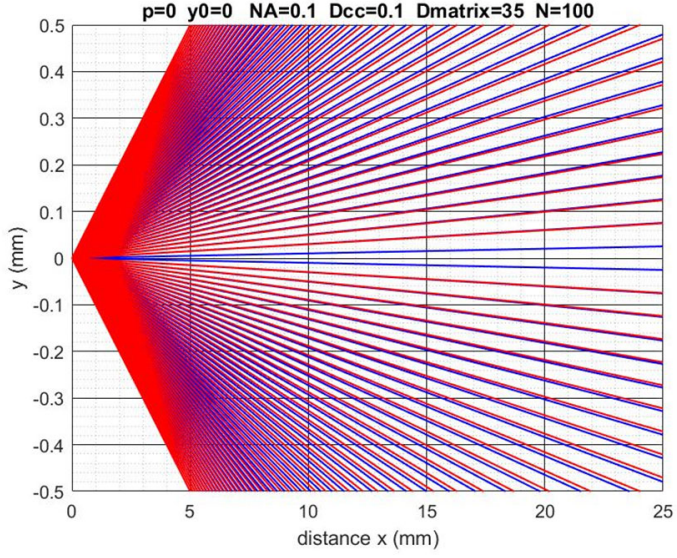

b) Focused ( $p=0), D_{C C}=100 \mu \mathrm{m}$; zoomed-in at fiber in array

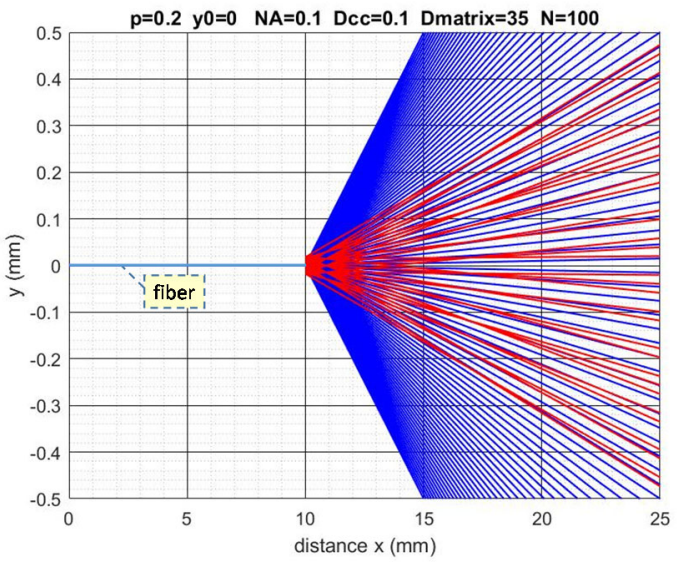

d) Defocused ( $p=0.2), D_{C C}=100 \mu \mathrm{m}$; zoomed-in at fiber in array

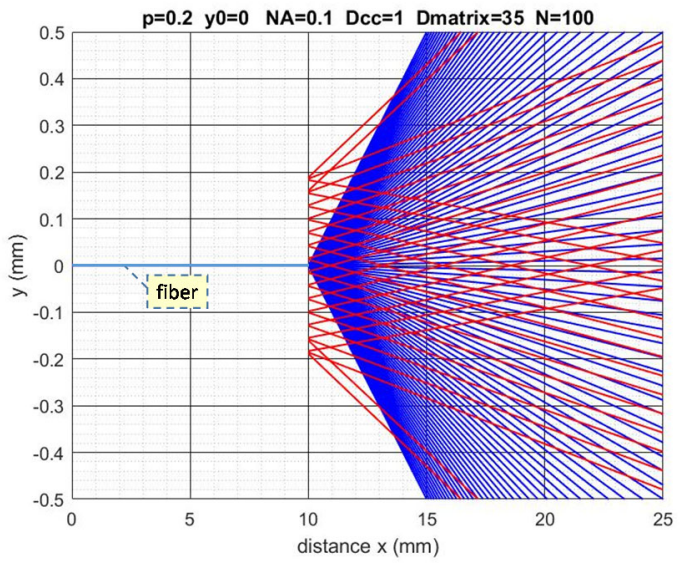

f) Defocused ( $p=0.2), D_{C C}=1 \mathrm{~mm}$; zoomed-in at fiber in array

Fig. 8 Ray tracing with $N=100$ rays when the $2 \mathrm{D}$ fiber array: in a) and b) is in focus; in c) and d) is $20 \%$ defocused w.r.t. lens and $C C$ diameter $D_{C C}=100 \mu$ m; in e) and f) is $20 \%$ defocused w.r.t. lens and $D_{C C}=1 \mathrm{~mm}$. Blue rays are running towards the corner cube array; red rays are returning from the CC array; lens f $=50 \mathrm{~mm}, \mathrm{CC}$ matrix diameter $D_{\text {matrix }}=35 \mathrm{~mm}$, distance lens-to-user area $b=2.5 \mathrm{~m}$. 


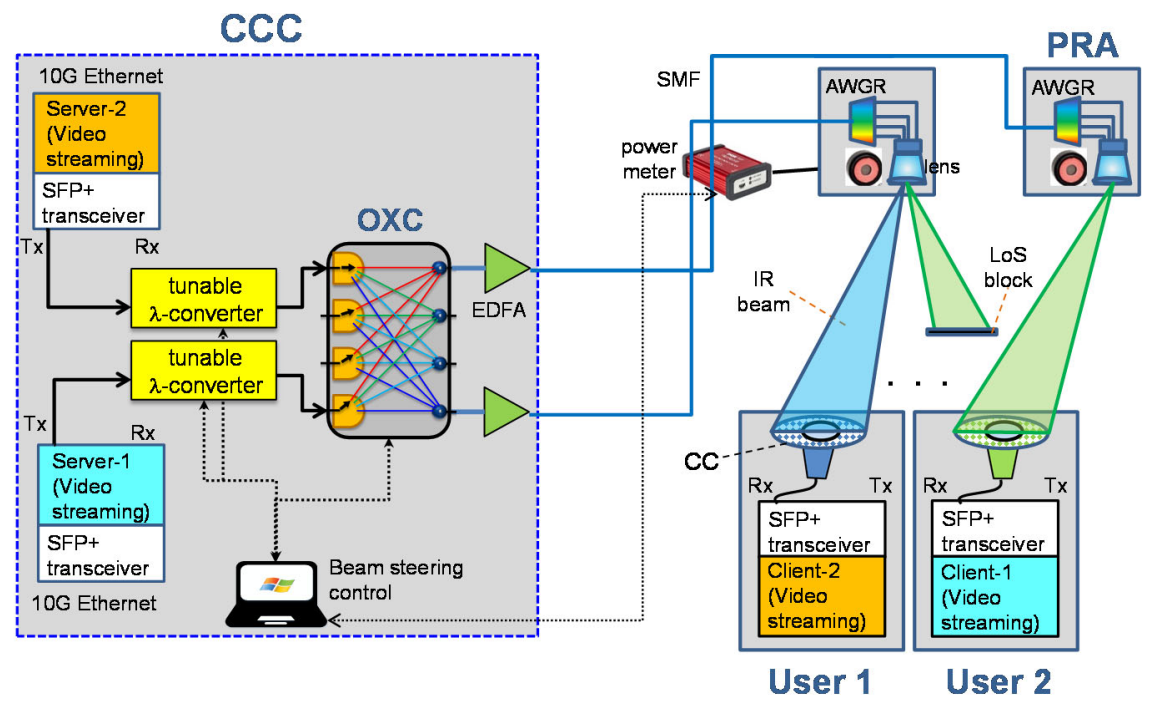

Fig. 9 Laboratory system demonstrator

in the lateral offset of the returning rays when the diameter of a $\mathrm{CC}$ is increased, and thus underline the need for a matrix array of miniature CC-s.

\section{SYSTEM EXPERIMENTS}

Our laboratory demonstrator setup is shown in Fig. 9. In order to extend the area of coverage, and also in order to circumvent possible line-of-sight blockings, it features two PRA-s which can be selected by the optical cross-connect (OXC) in the central site (CCC). Equipped with a $\mathrm{C}+\mathrm{L}$ band AWGR with channels spaced at $50 \mathrm{GHz}$ and $-3 \mathrm{~dB}$ bandwidths of $35 \mathrm{GHz}$ and $24 \mathrm{GHz}$ in the C-band and L-band, respectively, a PRA can launch up to 129 beams, each with diameter $\varnothing 10 \mathrm{~cm}$, and cover a user area of about $\varnothing 1.3 \mathrm{~m}$ at a reach of $2.5 \mathrm{~m}$. The OXC is composed of a $4 \times 4$ MEMS switch, with insertion losses of $7.0 \mathrm{~dB}$. In the demonstrator two user terminals are included, each equipped with a lens-based free-space optical receiver with $\varnothing 3 \mathrm{~cm}$ aperture. A $\varnothing 4 \mathrm{~cm} \mathrm{CC}$ foil with a central hole of $\varnothing 3 \mathrm{~cm}$ is mounted around this aperture. The physical details of the setup are shown by the photo in Fig. 10.

Two high-definition video streams are transmitted from the $\mathrm{CCC}$, each embedded in a $10 \mathrm{Gbit} / \mathrm{s}$ Ethernet stream. The video servers are equipped with SFP+ transceivers which are operated at a fixed wavelength. The tunable wavelength converters translate these video streams to the wavelengths appropriate for the $2 \mathrm{D}$ beam steering to the respective user terminals by the PRAs. Each user terminal is connected to a client for receiving the video stream, and displaying it on a monitor. Good real-time transmission of both video streams was achieved, with BER $<3 \cdot 10^{-12}$ at transmitted beam power of $6.0 \mathrm{dBm}$ and received power levels of -19 to $-23 \mathrm{dBm}$.

We included the passive localization function by attaching a circular piece of Orafol foil containing the miniature CC-s on an OWC receiver, as depicted in Fig. 9. Due to internal optical reflections in the PRA (we used a commercial $50 \mathrm{~mm} \mathrm{F/0.9}$ camera lens which was not anti-reflection coated for the $\lambda=1.5 \mu \mathrm{m}$ window, and connector joints between the $2 \mathrm{D}$ fiber array and the AWGR output fibers), we had to catch the returning rays by a small $\varnothing 1 \mathrm{~cm}$ power detector next to the lens. The optical power launched into the wireless channel was $6 \mathrm{dBm}$ in all the measurements. When the beam is scanning the user plane by tuning its wavelength, Fig. 11 shows the reflected power received by the localization detector for the case of two users, one equipped with a $\mathrm{CC}$ sheet with a diameter of $4 \mathrm{~cm}$ and the other of $5 \mathrm{~cm}$. There is a 1-to- 1 relation between the beam's wavelength and the device's position; hence the power peaks in Fig. 11 indicate the pico-cells where the devices are located. The height of the power peaks is related to the size of the $\mathrm{CC}$ sheet, as shown in Fig. 12. An adequate $\mathrm{SNR}>5 \mathrm{~dB}$ for the

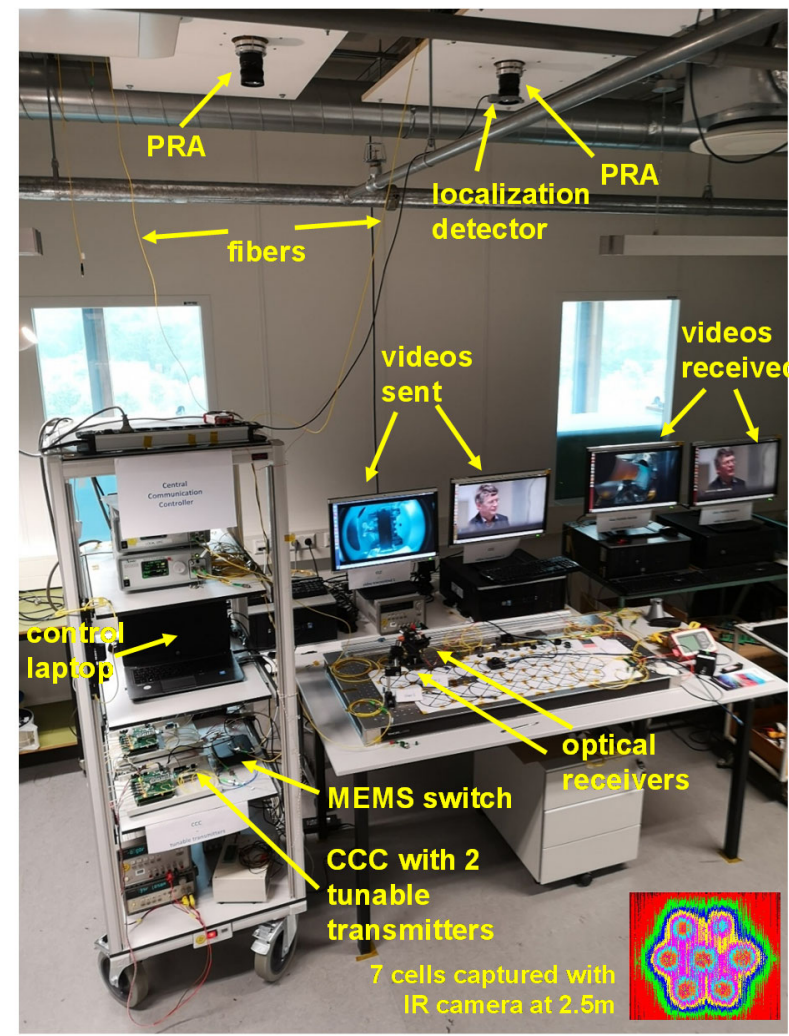

Fig. 10 Photo of laboratory demonstrator setup 
localization requires a $\mathrm{CC}$ foil diameter $>4 \mathrm{~cm}$. Background noise contributions are coming from the room illumination and from spurious reflections of the demonstrator table's surface. SNR values up to $15 \mathrm{~dB}$ have been achieved, which enabled localization clearly within the required resolution of a single pico-cell (diameter $10 \mathrm{~cm}$ ). Scanning the whole user area takes about $15 \mathrm{~s}$; the scan time is limited by the communication links between the power meter and the LABVIEW program running in the laptop which acts as localization processor and performs the beam steering control. The localization time is intrinsically constrained by the time needed to tune the wavelength of a laser diode over the full range for scanning the PRA's whole area, which can be done within a few milliseconds. However, the scanning process involves additional steps: the stepwise tuning to each cell consecutively, deciding whether there is retroreflected power from that cell exceeding the background noise level, and subsequently moving to the next cell. Per cell $115 \mathrm{~ms}$ is needed for all this, of which only a few ms is needed for the actual laser tuning, and the majority is taken by the Labview software running in the laptop controller, by the Arduino board which controls the laser tuning, and by the readout time of the localization power meter. Scanning the 129 cells in the area covered by the PRA thus takes about 15 seconds; this time may be reduced considerably by deploying more efficient algorithms implemented in embedded software.

The CC foil preferably surrounds the detector of the lensbased OWC receiver, which has an aperture of $\varnothing 3 \mathrm{~cm}$. Hence we also measured the returned localization power for a $\varnothing 4 \mathrm{~cm}$ $\mathrm{CC}$ foil with a central hole of $\varnothing 3 \mathrm{~cm}$ hosting the receiver's detector, and a $\varnothing 4 \mathrm{~cm}$ foil without hole. As shown in Fig. 13, the central hole caused a reduction of returned power of about $3.2 \mathrm{~dB}$ (theoretically $3.6 \mathrm{~dB}$ when uniformly illuminated).
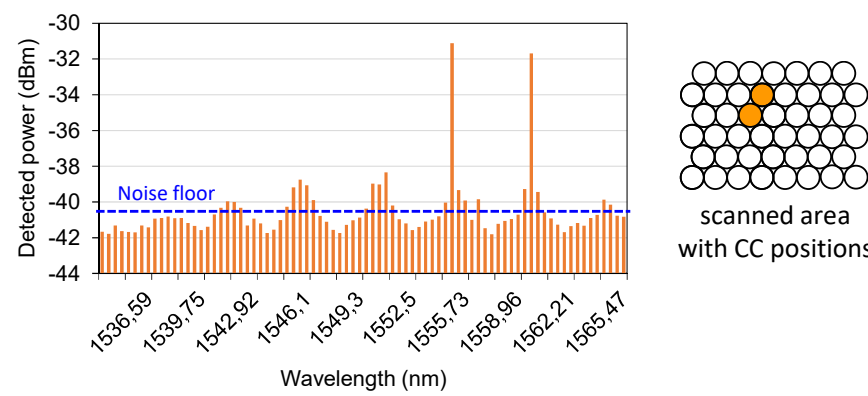

scanned area with CC positions

Fig. 11 Power received by localization detector when scanning across the system's pico-cells (for CC sheet diameter $\varnothing 4 \mathrm{~cm}$ )

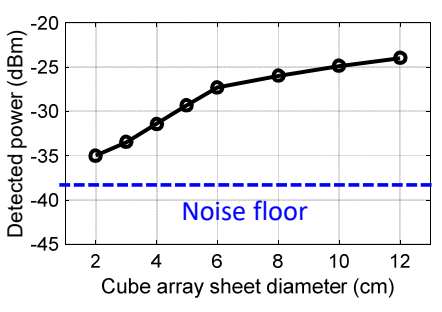

Fig. 12 Detected peak localization power vs. diameter of circular CC sheet

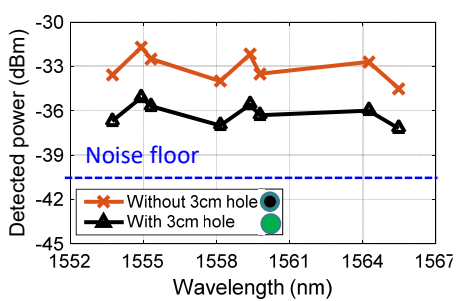

Fig. 13 Detected peak power vs. wavelength, for $\varnothing 4 \mathrm{~cm} C C$ foil with $\varnothing 3 \mathrm{~cm}$ hole, and $\varnothing 4 \mathrm{~cm} \mathrm{CC}$ foil without hole

\section{CONCLUDING REMARKS}

By means of narrow infrared optical beams on-demand, wireless links to individual users offering high capacity, high energy efficiency as well as strongly protected privacy can be established. This technology may enable highly-demanding broadband applications such as $8 \mathrm{~K}$ ultra-high definition wireless video streaming, real-time virtual reality gaming or training without being hampered by wires, tele-presence meetings, ... . Distinct advantages can be obtained in environments such as exhibition halls with frequently changing constellations of independent booths (which do not like capacity sharing), conference halls (where delegates want to download the proceedings instantly), electromagnetic radiation-sensitive areas (such as intensive care and surgery rooms in hospitals, inside airplanes, ...), airport waiting areas near the gate (where people want to do fast downloading or other voluminous internet things before getting on board), inside data centers between racks (where it provides minimum latency, as light travels $50 \%$ faster in air than in silica fiber), business meeting rooms requiring high privacy, etc., etc.

Efficient device localization is required in order to direct the beams on-demand and instantly to the user. Applying passive retro-reflection by means of a foil containing many miniature corner cubes has enabled device localization within the picocell resolution of our 2D beam-steered high-capacity optical wireless system setup. Real-time $10 \mathrm{GbE}$ video streaming to mobile devices has been demonstrated.

\section{REFERENCES}

[1] H. Haas, L. Yin, Y. Wang, and C. Chen, "What is LiFi?," J. Lightw. Technol., vol. 34, no. 6, pp. 1533-1544, Mar. 2016.

[2] A.M.J. Koonen, 'Indoor optical wireless systems: Technology, trends, and applications,' J. Lightw. Technol., vol. 36, no. 8, pp. 1459-1467, Apr. 2018, doi: 10.1109/JLT.2017.2787614.

[3] K. Wang, A. Nirmalathas, C. Lim, K. Alameh, and E. Skafidas, "Fullduplex gigabit indoor optical wireless communication system with CAP modulation," IEEE Photon. Technol. Lett., vol. 28, no. 7, Apr. 2016, pp. 790-793.

[4] A. Gomez, K. Shi, C. Quintana, M. Sato, G. Faulkner, B.C. Thomsen, and D.C. O'Brien, "Beyond $100-\mathrm{Gb} / \mathrm{s}$ indoor wide field-of-view optical wireless communications," Phot. Technol. Lett., vol. 27, no. 4, Feb. 2015, pp. 367-370.

[5] 'Laser safety', https://en.wikipedia.org/wiki/Laser safety, accessed Nov. $14,2019$.

[6] H. Liu, H. Darabi, P. Banerjee, J. Liu, 'Survey of Wireless Indoor Positioning Techniques and Systems,' IEEE Trans. on Systems, Man, and Cybernetics, vol. 37, no. 6, pp. 1067-1080, Nov. 2007.

[7] T.-H. Do and M. Yoo, 'An in-depth survey of visible light communication based positioning systems,' Sensors, vol. 16, no. 5, 2016, paper no. 678. On-line at http://www.mdpi.com/1424-8220/16/5/678 , accessed Nov. 14, 2019.

[8] A. Gomez, K. Shi, C. Quintana, G. Faulkner, B. C. Thomsen, and D. C. O'Brien, "A $50 \mathrm{~Gb} / \mathrm{s}$ transparent indoor optical wireless communications link with an integrated localization and tracking system," J. Lightw. Technol., vol. 34, no. 10, pp. 2510-2517, May 2016.

[9] A.M.J. Koonen, F. Gomez-Agis, F.M. Huijskens, K. A. Mekonnen, 'HighCapacity Optical Wireless Communication Using Two-Dimensional IR Beam Steering,' J. Lightw. Technol., vol. 36, no. 19, pp. 4486-4493, Oct. 2018.

[10] A.M.J. Koonen, K.A. Mekonnen, F.M. Huijskens, E. Tangdiongga, "Fully passive user localisation for beam-steered high-capacity optical wireless communication system," in Proc. ECOC2019, Dublin, paper Tu.3.C.4, Sep. 22-26, 2019.

[11]N.Q. Pham, K.A. Mekonnen, E. Tangdiongga, A. Mefleh, A.M.J. Koonen, "Accurate Indoor Localization for Beam-Steered OWC System 
Using Optical Camera," in Proc. ECOC2019, Dublin, Sep. 22-26, 2019, paper P45

[12]Photoelectric acrylic reflector material, https://www.orafol.com/en/europe/products/oralite-photoelectricsheeting, accessed Nov. 14, 2019.

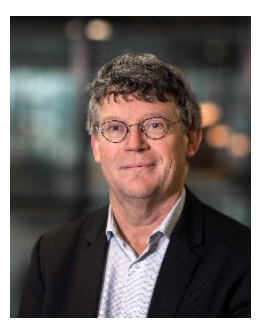

Ton Koonen (IEEE F'07, OSA F'13) is full professor in Eindhoven University of Technology (TU/e) since 2001. Since 2004, he is chairman of the group Electro-Optical Communication Systems, and since 2012 vice-dean of the department Electrical Engineering. From 2016 to 2019, he also was Scientific Director of the Institute for Photonic Integration at TU/e. Before 2001, he worked for more than 20 years in applied research in industry, amongst others in Bell Labs - Lucent Technologies. Ton Koonen is a Bell Labs Fellow (1998), IEEE Fellow (2007), OSA Fellow (2013), and Distinguished Guest Professor of Hunan University, Changsha, China (2014). In 2011, he received an Advanced Investigator Grant of the European Research Council on optical wireless communication. His current research interests are optical fibersupported in-building networks (including optical wireless communication techniques, radio-over-fiber techniques, and high-capacity plastic optical fiber (POF) techniques), optical access networks, and spatial division multiplexed systems.

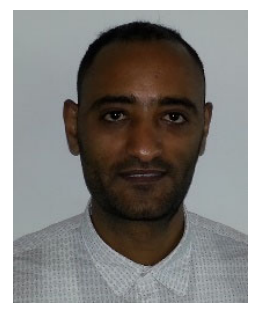

Ketemaw Addis Mekonnen (IEEE S'15) received the B.Sc. degree in electrical engineering from Mekelle University, Ethiopia, in 2007. He received the double M.Sc. degree in the Erasmus Mundus Master on photonic networks engineering program from Scuola Superiore Sant'Anna, Italy, and Aston University, U.K., in 2013. He obtained the Ph.D. degree in Eindhoven University of Technology, The Netherlands, in 2018. His current research interests include dynamic optical routing, radio over fiber, signal processing, and optical wireless communication.

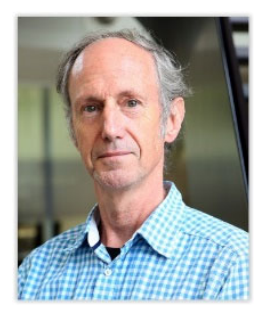

Frans Huijskens received the B Eng. in applied physics at the Technical College of Dordrecht, The Netherlands, in 1979. From 1981 to 1984, he was an Electronic Test Engineer at Siemens Gammasonics. In 1985, he joined the Electro-Optical Communications Group of Eindhoven University of Technology. He worked on passive fiber components, phase- and polarization-diversity coherent systems, on demonstrator setups of optical crossconnecting, optical packet switching, few-mode fiber transmission, and on packaging of optical integrated devices. Recently he has focused on demonstrator setups of optical wireless communication.

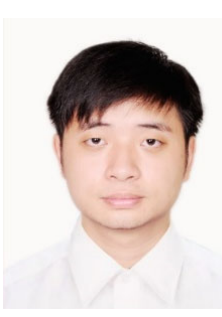

Ngoc-Quan Pham received the B.Eng. degree (talented program) in electrical engineering from Hanoi University of Science and Technology, Vietnam, in 2016. He received the M.Sc. degree in electronics engineering from Pukyong National University, South Korea, in 2018. Currently, he is pursuing the Ph.D. degree at Eindhoven University of Technology, The Netherlands. His current research interests include optical wireless communication, signal processing, indoor localization/tracking, and dynamic optical routing.

Zizheng Cao (IEEE S'11, M'15) received the M.Eng. degree in

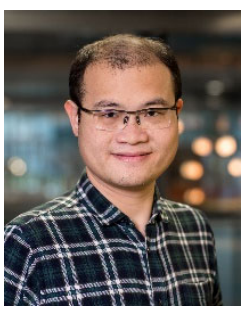
telecom engineering (awarded "Outstanding thesis of master degree" of Hunan Province) from Hunan University, Changsha, China, in 2010. He received the Ph.D. degree (Cum Laude) from Eindhoven University of Technology (TU/e) in 2015. Since then he is working at TU/e, where he currently is Assistant Professor. His research interests include integrated photonics circuits, microwave photonics, advanced DSP, and optical wireless communication. He received a Graduate Student Fellowship of IEEE Photonics Society in 2014. He holds two Chinese patents and two US provisional patents.

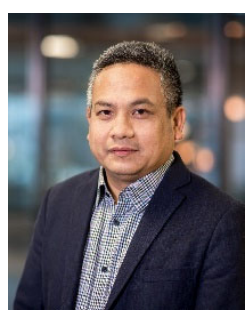

Eduward Tangdiongga (IEEE S'01, M'10) received the M.Sc. and Ph.D. degrees from the Eindhoven University of Technology, The Netherlands, in 1994 and 2001, respectively. In 2001, he joined COBRA Research Institute working on ultrafast optical signal processing using semiconductor devices. In 2016, he became an Associate Professor on advanced optical access and local area networks. His current research interests include passive optical networks, radio over (single mode-, multimode-, and plastic) fiber, and optical wireless communication. 